\title{
The Model of Ambulatory Clinical Education Environment Measure Instrument in Islamic Azad University Hospitals in Tehran
}

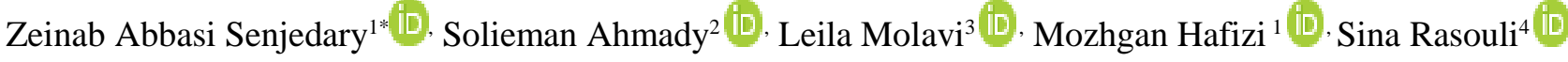 \\ ${ }^{1}$ Department of Midwifery, Nursing and Midwifery School, Medical Sciences Islamic Azad University, Tehran. Iran. \\ ${ }^{2}$ Department of Medical Education, Virtual School of Medical Education and Management,Shahid Beheshti Medical Sciences University, \\ Tehran, Iran. \\ ${ }^{3}$ Department of Operation Room Technology, Paramedical School, Medical Sciences Islamic Azad University, Tehran. Iran. \\ ${ }^{4}$ Industrial engineering student, Amirkabir University of Technology (Tehran Polytechnique), Tehran, Iran.
}

\section{Article Info

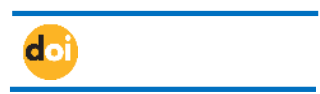

Article history:

Received 2 May 2020

Accepted 4 Feb 2020

Published 10 Mar 2021

Keywords:

Education Environment,

ACLEEM,

Construct Validity,

Confirmatory factor analyses

*Corresponding author:

Zeinab Abbasi Senjedary, Department of Midwifery, Nursing and Midwifery

School, Medical Sciences Islamic Azad

University, Tehran. Iran.

Email:abasi.zeinab@yahoo.com

\section{Abstract}

Background \& Objective: Recently medical education has been significantly evolution. One of thes evolution has been a progressive reduction in time that medical students to spend in hospitals as well as changes in the profiles of hospitalized patients. The aim of this study was to develop the model of outpatient clinical education environment measure in interns of Islamic Azad University, Tehran medical branch.

Materials and Methods: This study was a cross sectional design. Participants of the study were 250, of interns of two university hospitals of Islamic Azad University, Tehran Medical Branch in 2017. Construct validity of ACLEEM instrument was assessed for to development of the model. Exploratory Factor Analyses (EFA) and Confirmatory Factor Analyses (CFA) was measured. Convergent and discriminant validities were determined. The Pearson correlation coefficient, Inter-Class Coefficient (ICC) were used to evaluate the stability of each research construct. The reliability of instrument was measured by Cronbach's alpha coefficient.

Results: In EFA of the ACLEEM, the Kaiser-Meyer-Olkin (KMO) index was 0.83 and Bartlett's test was significant $(\mathrm{P}<0.001)$.The eight extracted factors of instrument had explained 60.73 percent of the variance after varimax rotation .Confirmatory factor analyses revealed the model of study. The instrument has a good fit and convergence and discriminant narrative. The internal consistency of instrument was $>0.8$ and ICC was between $0.61-0.85$ and the reliability of instrument was 0.81 .

Conclusion: Overall, ACLEEM showed excellent measurement model and construct validity in an Iranian outpatient setting.

\section{Introduction}

Recently medical education has been a significant evolution. One of these evolution has been a progressive reduction in time that medical students to spend in hospitals as well as changes in the profiles of hospitalized patients (1). In medical education, high-quality education is a vital and educational environment is underpinned by research outcomes and success (2). As a result, several instruments have been developed to measure medical educational environment quality, however, there is no consensus about which concept based on theoretical framework should be measured (3). A recently conducted study revealed that the new medical educational environment instruments are many different attributed to the fact that the instruments are often tailored to a specific set of interests (4). The teaching methods used in outpatient clinics are fundamentally different from those used inwards (5).In contrast, outpatient clinics offer more diverse and effective educational opportunities and relationships (6). Several studies have been conducted to validate instruments developed for the assessment of learning environments of the inpatient setting, in medical education, such as Postgraduate Hospital Educational Environment Measure (PHEEM) (7), Clinical Learning Environment Scale (8), and Dundee Ready Education Environment Measure (DREEM) (9). But there is scares instrument to evaluate out-patient setting. One of the inventory was designed to measure the educational environment of ambulatory care was ACLEEM. In the 2012, Arnoldo Riquelume designed an inventory to measure the educational 
environment of ambulatory setting was named Ambulatory Clinical Learning Education Environment Measure (ACLEEM) in Chili. The questionnaire was developed and valid based on grounded theory and a modified Delphi procedure (10). Having recognized this, we considered, Several studies were conducted to measure the outpatient clinical education environment by ACLEEM instrument but this evidence is limited. There is little evidence from other countries $(10,11,12)$. The first study was conducted by Riquelme et al (10). Another study revealed the ambulatory learning environment measure in dental students in Bangladesh (11). Farque et al in 2017concluded that the ACLEEM instrument was valid and reliable to measure outpatient setting (12).

In Iran, some studies were identified. A study conducted by Parvise et al (2016) investigated the psychometric properties of ACLEEM on residents in Shiraz University (13). About four studies have been conducted to report on resident's attitudes towards an outpatient educational and learning environment based on eight subscales derived by Riquelme et al (10, 14, $15,16,17)$. But there is no study to design the model of the factor structure of ACLEEM in a medical intern's outpatient setting in Iran. For design, a model of the instrument the construct validity should be determined. Construct validity is the extent to which the measurements used, often questionnaires, actually test the hypothesis or theory they are measuring $(18,19)$. Addressing this concern, the aim of this study was to develop the model of ACLEEM instrument in the outpatient setting in Tehran.

\section{Materials and Methods}

This cross-sectional study was conducted on year 6 and year 7 interns of two teaching hospitals of Islamic Azad University, Tehran Medical Branch in 2017. Research samples were selected by convenience sampling method. The sample size met the criteria for acceptable sample size and at last 250 required for EFA and CFA for a questionnaire comprising 50 items. In measuring of sample adequacy, two indicates have been used, Kaiser-Meyer-Olkin (KMO) and Bartlett's Test of Sphericity (BTS). The sample is adequate if (KMO) is greater than 0.6 and (BTS) is significant at $\mathrm{p}<0.01(20)$. The inclusion criteria of the study were being the internships of the hospitals and at least two weeks have passed of their internship at that hospital and be willing to participate in the study. The researcher spent 2 months in each one of the hospitals. Interns usually attach one-month internships in every department. After to explain the objectives of the research and gaining satisfaction, informed written consent was obtained before questionnaires were distributed. The interns also ensured that participation in the study is voluntary and anonymous, each intern filled the questionnaire by itself. Questionnaires were collected during the same shift. Data collection tool include ACLEEM questionnaire. The ACLEEM is a 50 -item inventory containing the following subscales: Quality of clinical teachers (12 questions), clinical activates and patient care (11 questions), protected time for non-clinical activities (5 questions), infrastructure (6 questions), clinical skills (6 questions), assessment and feedback (4 questions), Information, communication, and technology (3 questions), and clinical supervision (3 questions). Each item on the ACLEEM is scored on a 5-point Likert scale ranging from 0 (strongly disagree) to 4 (strongly agree), giving a possible total score of 200 (10). Structural equation Modeling (SEM) is a confirmatory factor technique for exploratory purpose. CFA depicts the patterns of observed variables extracted by exploratory factor analyses with Varimax rotation. Convergent validity, Variance Extracted, Convergent Reliability and discriminant validities are four sizes have been used in construct validity. Discriminant validity was supported whenever the correlation between an item and its hypothesized domain was higher than its correlation with the other domains. CFA can be used in scale development, testing the appropriateness of measures and to examine the use of the measure in a model (21). The fit of the model was assessed by combining the following fit indices: the Comparative Fit Index (CFI), the 
Normed Fit Index (NFI), and the Root Means and Square Error of Approximation (RMSEA). Predetermined cut-off values was used to assess the fit (CFI and NFI >0.95, for a good fit and RMSEA $<0.06$ for a good fit (22). The reliability of the 50item questionnaire was confirmed with Cronbach's alpha (10). The Pearson correlation coefficient, Intra-Class Correlation Coefficient (23) were used to evaluate the stability of each research construct. All analyses were performed in SPSS version 23and Lisrel 8.7 (24)

\section{Ethical consideration}

This study was approved by the deputy of research and technology of Islamic Azad University, Tehran Medical Branch. The aim of the study was described for the medical students and informed written consent was obtained. The questionnaire was anonymous and all of the interns filled it alone.

\section{Results}

The findings of the study revealed that 250 interns, responded to the questionnaire, the response rate $100 \%$. Five questionnaires were incomplete and was omitted. Of these, 186 (75.9\%) were female, 59 (24.1\%) were male. About 143of respondents (\%58.4) were in Boali hospital and 102 (\%41.6) were in Amir Hospital. Participants' ages were distributed ranging from 24 to 28 years, with the majority more than 29 years old 100 (\%40.8). The majority of respondents $110(\% 44.9)$ were internal ward intern, and most $60(\% 24.5)$ were interns of the surgical ward and $75(\% 30.6)$ were in minor ward (Table1).

Table 1: Demographic characteristics of participants

\begin{tabular}{lll}
\hline Department & Internal & $110(44.9)$ \\
& Surgical & $60(24.5)$ \\
& Minor & $75(30.6)$ \\
\hline gender & female & $186(75.9)$ \\
& male & $59(24.1)$ \\
\hline Age & $<24$ & $55(22.4)$ \\
& $24-28$ & $90(36.7)$ \\
& $29 \leq$ & $100(40.8)$ \\
\hline Hospitals & Buali & $143(58.4)$ \\
& Amirlalmomenin & $102(41.6)$ \\
\hline
\end{tabular}

Six steps was perform for exploratory factor analysis. At first, we used the KMO index and Bartlett test for measurement of sampling adequacy (Table 2) (20)

Table 2- KMO index and Bartlett test of ACLEEM questionnaire

\begin{tabular}{lll}
\hline KMO index & & 0.83 \\
\hline \multirow{3}{*}{ Bartlett's test } & $\mathrm{X}^{2}$ statistic value & 6577.19 \\
\cline { 2 - 3 } & Degree of freedom & 1225.00 \\
\cline { 2 - 3 } & P-value & $\mathrm{P}<0.01$ \\
\hline
\end{tabular}


The KMO index measure was 0.83 greater than 0.6 and Bartlett's test was significant $\mathrm{p}<0.01$, so the sample size was adequate for this test. Then, EFA extraction was conducted with 50 items questionnaire. We determined the contribution of each item in explaining the variance of the instrument. Any items didn't have the shared variance less than $50 \%$ of variance will have been excluded and any items were not excluded. At third step, we used three methods of the Kaiser criterion (Eigenvalue method), cumulative variance and pebble diagrams (Fig 1).

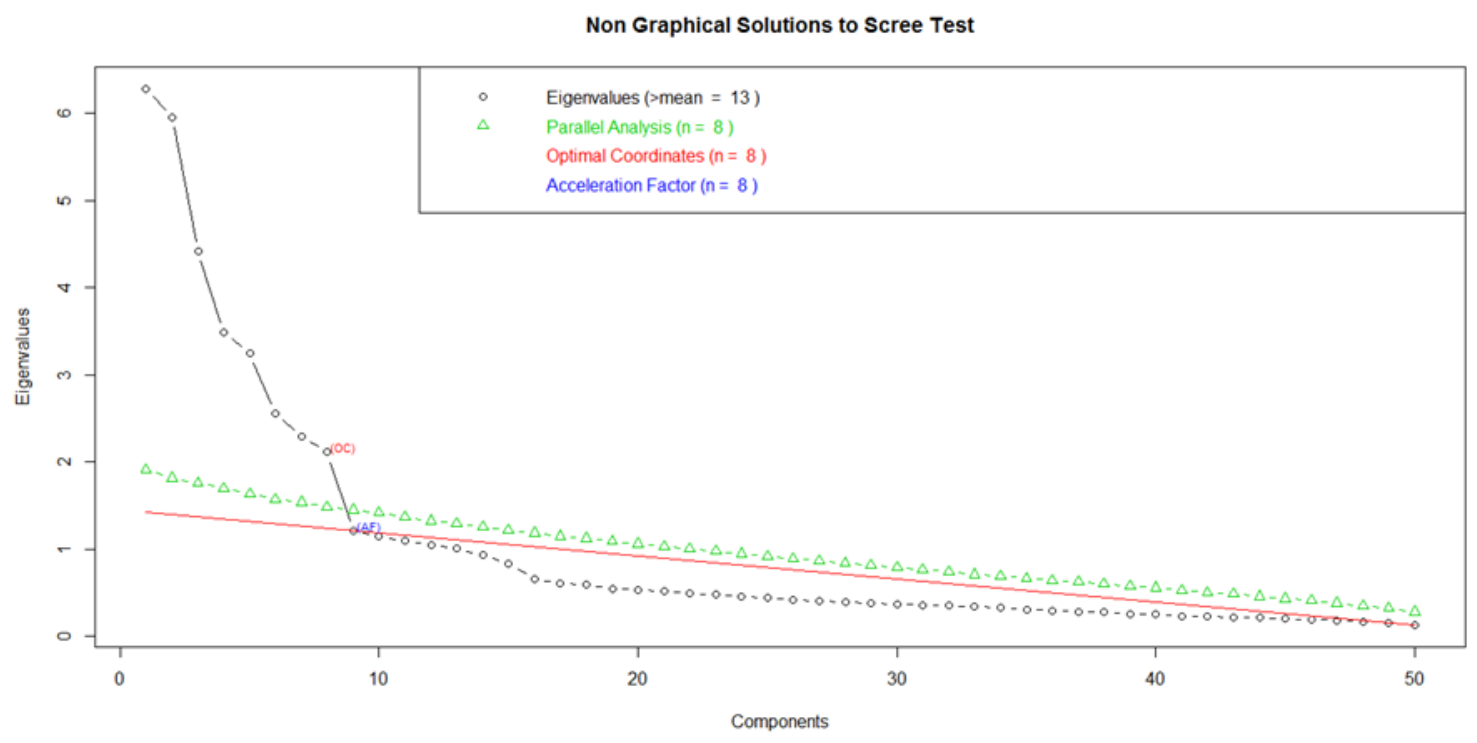

Figure 1- Pebble diagram of ACLEEM questionnaire items factors

As shown in (Table 3), eight factors extracted from these 50 items, and the seven-item with the variance of less than $50 \%$, was been omitted. These include items 2, 10, 12, 21, 23, 32 and 39 (Table7).At the fourth step, we investigated the correlation between extracted factors and questionnaire items. At the fifth step we rotated agents if necessary and we sorted items into agents and at least we named the factors base on the correlation between questions related to each factor and the main questionnaire of the construct (Table3). At this study, the minimum factor loading cut point was 0.4. The eight extracted factors of instruments had accumulated 60.73 percent of the variance. Also, concerning the significance of Bartlett test, $(\mathrm{p}<0.01)$, There is a significant inter-correlation between items of each factor that was extracted and there is no significant correlation between each factor and other factors. Then we confirm the factor analysis of the extracted factors related to the ACLEEM questionnaire scale through confirmatory analyses by using Liserl software, to investigate the factor structure of the learning environment through CFA. The reliability of the 43-item questionnaire was confirmed with Cronbach's alpha was 0.81 (Table4). 
Table 3: Exploratory factor analyses after rotation and removal of items with proof fit.

\begin{tabular}{|c|c|c|c|c|c|c|c|c|}
\hline \multirow{2}{*}{ items } & \multicolumn{8}{|c|}{ Factors } \\
\hline & 1 & 2 & 3 & 4 & 5 & 6 & 7 & 8 \\
\hline 1 & 0.78 & -0.05 & -0.04 & 0.08 & -0.05 & 0.03 & -0.06 & -0.11 \\
\hline 2 & 0.86 & 0.03 & 0.13 & 0.07 & -0.01 & 0.06 & 0.03 & 0.06 \\
\hline 3 & 0.84 & -0.02 & -0.08 & -0.05 & 0.05 & 0.02 & -0.01 & -0.12 \\
\hline 4 & 0.85 & 0.00 & 0.02 & 0.00 & -0.01 & -0.04 & 0.01 & 0.02 \\
\hline 5 & 0.83 & 0.08 & 0.08 & 0.05 & -0.07 & 0.06 & -0.01 & -0.06 \\
\hline 6 & 0.84 & 0.00 & 0.06 & 0.05 & -0.03 & 0.04 & 0.01 & -0.04 \\
\hline 7 & 0.79 & -0.05 & -0.02 & -0.01 & -0.01 & 0.00 & -0.01 & -0.05 \\
\hline 8 & 0.83 & 0.04 & -0.06 & 0.06 & -0.03 & 0.05 & 0.01 & 0.11 \\
\hline 9 & 0.81 & 0.00 & -0.03 & -0.02 & -0.01 & -0.03 & 0.001 & 0.02 \\
\hline 10 & -0.01 & 0.80 & -0.06 & -0.07 & 0.04 & 0.00 & 0.00 & 0.08 \\
\hline 11 & 0.11 & 0.78 & -0.05 & -0.03 & -0.05 & -0.03 & -0.02 & -0.02 \\
\hline 12 & -0.03 & 0.78 & 0.10 & -0.13 & 0.01 & 0.05 & 0.13 & -0.06 \\
\hline 13 & 0.02 & 0.77 & 0.05 & 0.09 & 0.07 & -0.01 & 0.05 & -0.02 \\
\hline 14 & -0.05 & 0.78 & 0.00 & -0.03 & 0.08 & -0.01 & 0.07 & 0.01 \\
\hline 15 & -0.02 & 0.79 & -0.05 & -0.03 & 0.05 & 0.02 & 0.11 & 0.05 \\
\hline 16 & 0.02 & 0.82 & -0.03 & -0.03 & 0.00 & 0.03 & -0.06 & -0.03 \\
\hline 17 & 0.01 & 0.84 & 0.02 & 0.04 & -0.05 & 0.02 & -0.01 & 0.00 \\
\hline 18 & 0.01 & 0.83 & -0.01 & 0.04 & 0.07 & 0.00 & -0.03 & 0.00 \\
\hline 19 & -0.02 & 0.08 & 0.07 & 0.05 & 0.83 & 0.05 & -0.06 & 0.05 \\
\hline 20 & 0.02 & 0.03 & 0.05 & 0.05 & 0.82 & 0.07 & 0.04 & 0.07 \\
\hline 21 & -0.06 & 0.06 & 0.03 & 0.05 & 0.83 & 0.02 & -0.02 & 0.04 \\
\hline
\end{tabular}




\begin{tabular}{|c|c|c|c|c|c|c|c|c|}
\hline 22 & -0.04 & 0.00 & 0.06 & 0.06 & 0.84 & 0.05 & -0.03 & 0.01 \\
\hline 23 & -0.03 & 0.03 & 0.07 & 0.00 & 0.82 & -0.02 & 0.12 & -0.05 \\
\hline 24 & -0.02 & -0.10 & 0.02 & 0.84 & 0.02 & -0.04 & 0.03 & -0.03 \\
\hline 25 & 0.05 & -0.03 & 0.00 & 0.83 & 0.05 & 0.03 & -0.03 & -0.04 \\
\hline 26 & -0.01 & -0.04 & 0.09 & 0.85 & 0.02 & -0.02 & -0.01 & 0.07 \\
\hline 27 & 0.12 & 0.01 & 0.07 & 0.84 & 0.01 & -0.02 & 0.03 & 0.03 \\
\hline 28 & 0.06 & 0.05 & 0.00 & 0.82 & 0.11 & -0.01 & -0.04 & 0.10 \\
\hline 29 & 0.04 & -0.02 & 0.82 & 0.02 & 0.06 & 0.03 & 0.08 & 0.01 \\
\hline 30 & 0.03 & 0.00 & 0.86 & 0.05 & -0.02 & -0.02 & 0.02 & -0.01 \\
\hline 31 & -0.03 & -0.01 & 0.83 & 0.07 & 0.13 & 0.00 & -0.07 & -0.07 \\
\hline 32 & 0.05 & 0.05 & 0.85 & 0.02 & 0.04 & -0.01 & 0.01 & -0.01 \\
\hline 33 & -0.04 & -0.07 & 0.87 & 0.01 & 0.07 & 0.01 & -0.01 & -0.01 \\
\hline 34 & 0.06 & -0.02 & -0.11 & 0.00 & -0.03 & 0.78 & 0.16 & -0.06 \\
\hline 35 & 0.06 & 0.07 & 0.02 & -0.07 & 0.01 & 0.80 & 0.00 & 0.01 \\
\hline 36 & 0.03 & 0.02 & 0.08 & 0.00 & 0.05 & 0.83 & -0.08 & 0.03 \\
\hline 37 & -0.02 & -0.03 & 0.01 & -0.06 & 0.14 & 0.80 & 0.02 & 0.01 \\
\hline 38 & 0.02 & 0.05 & 0.03 & 0.00 & 0.05 & 0.02 & 0.88 & 0.03 \\
\hline 39 & -0.03 & 0.04 & -0.06 & 0.01 & 0.04 & 0.08 & 0.85 & 0.00 \\
\hline 40 & -0.01 & 0.08 & 0.06 & -0.02 & -0.05 & -0.01 & 0.84 & 0.00 \\
\hline 41 & -0.02 & 0.00 & -0.05 & 0.00 & -0.01 & 0.02 & 0.01 & 0.85 \\
\hline 42 & -0.02 & 0.02 & -0.07 & -0.04 & 0.08 & -0.07 & 0.02 & 0.84 \\
\hline 43 & -0.09 & -0.02 & -0.03 & 0.07 & 0.04 & 0.04 & -0.01 & 0.83 \\
\hline
\end{tabular}


Table 4: Pearson correlation coefficient, inter- correlated correlation coefficient (ICC) and Alpha Cronbach

\begin{tabular}{|c|c|c|c|c|c|c|}
\hline Construct & Lable of constructs & $\begin{array}{l}\text { Number } \\
\text { of items }\end{array}$ & $\begin{array}{l}\text { Pearson's } \\
\text { coefficient }\end{array}$ & $\begin{array}{l}\text { Inter correlated } \\
\text { correlation }\end{array}$ & $\begin{array}{c}P \text { - value } \\
\text { paired } t \text {-test }\end{array}$ & Alpha Cronbach \\
\hline $\mathrm{F} 1: \mathrm{ECP}$ & $\begin{array}{l}\text { Educational clinical } \\
\text { empowerment }\end{array}$ & 9 & 0.84 & 0.81 & 0.41 & 0.94 \\
\hline $\mathrm{F} 2: \mathrm{CPP}$ & $\begin{array}{l}\text { Clinical filed activity } \\
\text { and practical care }\end{array}$ & 9 & 0.73 & 0.65 & 0.12 & 0.92 \\
\hline F3:TNCA & $\begin{array}{l}\text { Time for non-clinical } \\
\text { activities }\end{array}$ & 5 & 0.85 & 0.81 & 0.38 & 0.88 \\
\hline F4:INF & infrastructure & 5 & 0.81 & 0.72 & 0.36 & 0.79 \\
\hline F5:CS & clinical skills & 5 & 0.85 & 0.89 & 0.6 & 0.9 \\
\hline $\mathrm{F} 6: \mathrm{MF}$ & $\begin{array}{l}\text { Measurement and } \\
\text { feedback }\end{array}$ & 4 & 0.75 & 0.71 & 0.48 & 0.82 \\
\hline F7:ICF & $\begin{array}{l}\text { Information, } \\
\text { communication and } \\
\text { Technology }\end{array}$ & 3 & 0.79 & 0.82 & 0.26 & 0.82 \\
\hline F8:CSF & Clinical Audit & 3 & 0.76 & 0.79 & 0.25 & 0.79 \\
\hline Total & & 43 & 0.8 & 0.78 & 0.32 & 0.81 \\
\hline
\end{tabular}

\section{Confirmatory Factor Analyses}

The standardized eight-factor model is shown in Figure 2, including educational clinical empowerment (9 items), clinical filed activity and practical care (9 items), time for non-clinical activities (5 items), infrastructure (5 items), clinical skills (5 items), measurement and feedback (4 items), information communication and technology (3 items) and clinical audit (3 items). The covariance between latent variables is shown by a double-headed arrow. The parameter estimation is based on the standardized output of
CFA. According to the measures related to fitness indicators, CFI $=0.98, \mathrm{NFI}=0.98, \mathrm{PMSEA}=0$. Th is structure is in good and at least an acceptable level in terms of all fitness indicators (Table 5). As shown in Table 6, the Construct Validity is more than 0.7 and p-value $<0.05$ and Construct Validity is greater than Average Extracted Variance (AVE) for convergence and for discrimination AVE is greater than the Maximum Shared Squared Variance AVE $>M S V$ and MSV is greater than Average Shared Squared Variance(ASV). 
Table 5: Overall fit indices of the CFA model

\begin{tabular}{|c|c|c|c|c|}
\hline \multirow{3}{*}{$\begin{array}{l}\text { The Goodness of Fit } \\
\text { Index (GFI) }\end{array}$} & Index limits & Index limits & Goodness index & \multirow{3}{*}{ Result } \\
\hline & & & & \\
\hline & For acceptable fit & For a good fit & Observed fit & \\
\hline $\mathrm{X}^{2}$,Freedom degree & $\frac{x 2}{\begin{array}{l}\text { freedom } \\
\text { degree }\end{array}}<3$ & $\frac{x 2}{\begin{array}{c}\text { freedom } \\
\text { degree }\end{array}}<5$ & $923 / 36(832)$ & Good Fitness \\
\hline P-value & & & $\mathrm{P}<0.05$ & \\
\hline RMSEA & $0.08<$ & $0.05<$ & $0.02<$ & Good Fitness \\
\hline PRMSEA & $0.05<$ & $0.1<$ & $0.99<$ & Good Fitness \\
\hline CFI & $0.90<$ & $0.95<$ & $0.98<$ & Good Fitness \\
\hline NNFI & $0.90<$ & $0.95<$ & $0.98<$ & Good Fitness \\
\hline
\end{tabular}

Table 6: Convergence and discrimination of ACLEEM

\begin{tabular}{|c|c|c|c|c|}
\hline Indexes & Construct Validity & $\begin{array}{l}\text { Average Variance } \\
\text { Extracted (AVE) }\end{array}$ & $\begin{array}{l}\text { Maximum Shared Squared } \\
\text { Variance (MSV) }\end{array}$ & $\begin{array}{c}\text { Average Shared Squared } \\
\text { Variance(ASV) }\end{array}$ \\
\hline ICT & 0.83 & 0.62 & 0.01 & 0.00 \\
\hline ECP & 0.94 & 0.64 & 0.01 & 0.00 \\
\hline $\mathrm{CPP}$ & 0.93 & 0.62 & 0.01 & 0.00 \\
\hline TNCA & 0.89 & 0.62 & 0.02 & 0.01 \\
\hline INF & 0.90 & 0.64 & 0.01 & 0.01 \\
\hline $\mathrm{CS}$ & 0.90 & 0.66 & 0.02 & 0.01 \\
\hline MF & 0.82 & 0.53 & 0.01 & 0.00 \\
\hline CSU & 0.80 & 0.57 & 0.01 & 0.00 \\
\hline
\end{tabular}

The Construct Validity is more than 0.7 and pvalue $<0.05$ and Construct Validity is greater than Average Extracted Variance (AVE) for convergence and for discrimination AVE is greater than the Maximum Shared Squared Variance AVE $>M S V$ and MSV is greater than Average Shared Squared Variance (ASV). 
Figure 2: Confirmatory factor analysis model of the ACLEEM questionnaire with standard factor loadings

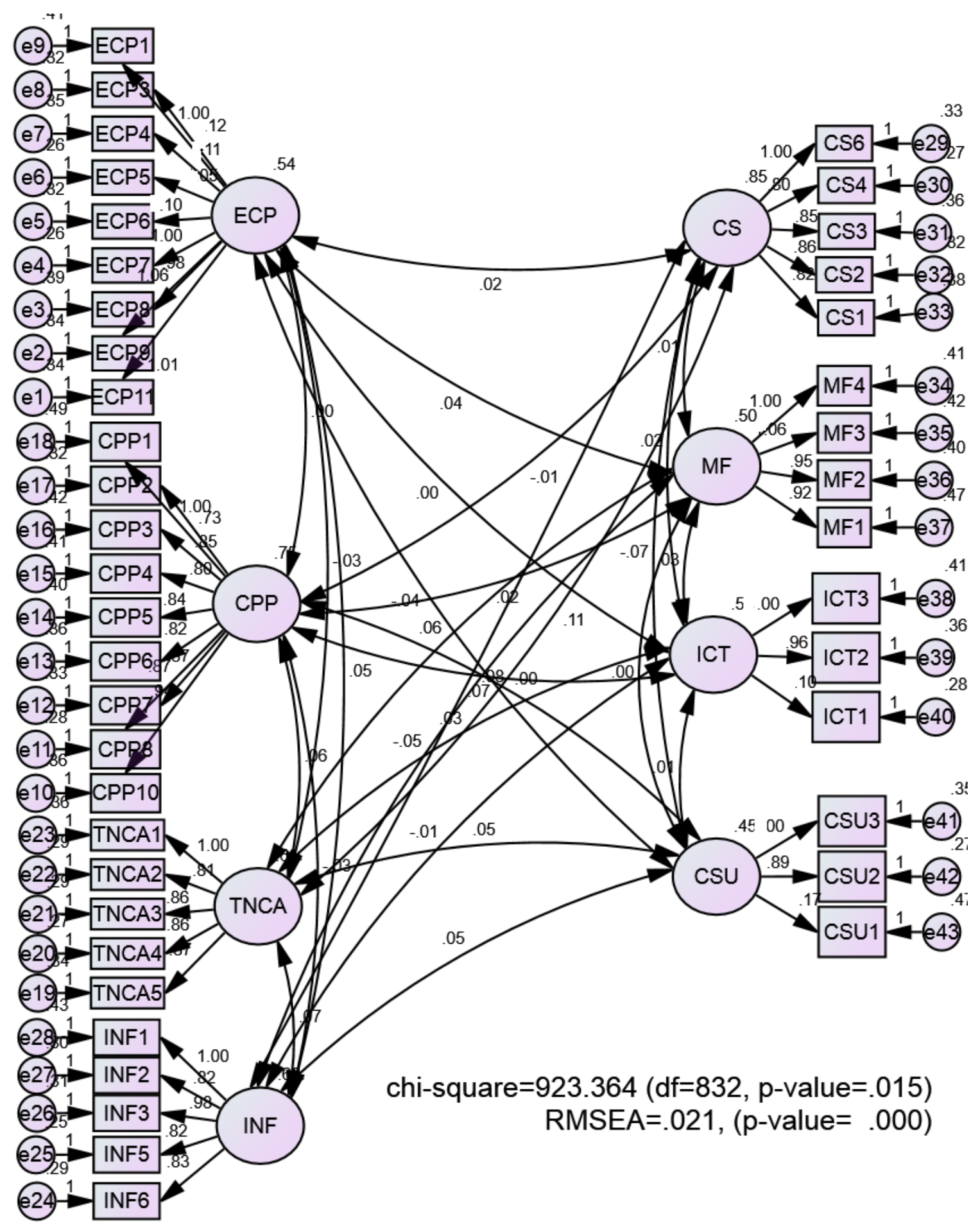

\section{Discussion}

The model of ACLEEM was developed. According to the measures related to fitness indicators, this model is in good and at least an acceptable level in terms of all fitness indicators. The only indicator that this model does not have a good fit is the p-value $=1$ of the $\mathrm{X} 2$ test. But other measures related to fit such as Comparative
Fit Index CFI $=0.98$, Normed Fit Index NFI=0.98, Root Mean Square of Error Approximation PMSEA $=0$. Revealed good fit (table5). It is for the first time in Iran that the model of ACLEEM was developed. The exploratory factor analysis revealed eight factors and confirmatory factor analysis was confirm the extracted factors. The 
analysis has extracted eight factors of learning environment including Educational clinical empowerment (9 items), Clinical filed activity and practical care (9 items), Time for non-clinical activities (5 items), infrastructure (5 items), clinical skills (5 items), Measurement and feedback (4 items), Information, communication and technology (3 items) and Clinical Audit (3 items). This eight extracted factors of the Persian version of the instrument were similar to eight factors extracted by Rediqule et al (2010), the inventor of the instrument (10), Moghari et al (2015) (15) and Haque et al (11), Kuhpayezadeh et $\mathrm{al}(2014)(16)$, Rahmani et $\mathrm{al}(2018)(17)$. However, the items were distributed differently in the domains of the Persian questionnaire and in our study seven items have been deleted (items 2 , 10, 12, 21, 23, 32 and 39) (Table 7). However, a large mismatch in structure was observed compared to the original version. The Study conducted by Parvise et al revealed that the majority of the questions in ACLEEM were included in the Persian version of ACLEEM questionnaire, but these items distributed in three domains, including clinical teaching (items 1-16), clinical training (items 17-38), and support (items 39-50). (11). the results of this study are not in line with our study (11). Because we extracted eight factors and in our study 7 items of the questionnaire was omitted. This may imply that the study interns had a different perception toward some items. In other words, the Persian version of this questionnaire could have a different structure. Thus, another factor analysis could be performed for finding more domains in the Persian version of this instrument. The goodness of fit indices of CFA indicated a good fit for the collected data and the model design in our study was in line with the study conducted by Faruque (20). In our study, the reliability of the instrument Cronbach's alpha coefficients was 0.81 , which is in line with the results of the study by Riquelme and Parvise et al $(10,13)$. Additionally, inter-item correlations were $>0.70$ for all eight subscales and all standard operating loads are greater than 0.5 and therefore the existence of any of the questions (items) in this structure is confirmed. Thus, the reliability of the Persian version of the ACLEEM questionnaire was confirmed. Based on table 6, Average Extracted Variance (AVE) is greater than Averaged Shared Squared variance (ASV). It can be concluded that this structure has a discriminative narrative and our results have confirmed. This finding is alike Parvise et al study (13). Although the learning environment instrument has been validated in the previous studies, developing the model and conducting CFA in our study will ensure the extracted factors and construct validity of the instrument (21).

The present study has an innovation. For the first time, our study to develop the model of ambulatory care education environment among interns of medical students in Iran. Our study has some limitations. First, we used a cross-sectional study design, second our results may be influenced by selection bias and should be interpreted cautiously. With this validated questionnaire, the future research of the learning environment will get benefit from the modelling aspect. The questionnaire is applicable to measure the learning environment that has been supported widely by many studies. The present study can be extended to different settings and samples to achieve a better measurement model. It is hoped that by validating the learning environment instrument, more upcoming related issues will be conducted in the future to facilitate students' learning.

\section{Conclusion}

The final developed model of the Persian version of the ACLEEM instrument is a good design that can be used for to measure education environment in outpatient setting of medical students in Iran.

\section{Acknowledgments}

We would like to appreciate the manager of the hospitals of Medical Sciences Islamic Azad University for good cooperation for this thesis.

Conflicts of Interest: The authors declare that there are no conflicts of interest. 
Table7: Ambulatory Clinical Learning Educational Environment Measure (ACLEEM)

\section{Domains and items}

\begin{tabular}{|c|c|}
\hline \multicolumn{2}{|c|}{ Empowering clinical teachers } \\
\hline 1 & Working in outpatient clinics enable me to improves my problem-solving skills \\
\hline 2 & Training staff in outpatient clinics have up to date in good clinical skills. \\
\hline 3 & Training staff in outpatient clinics have up-to-date skills and knowledge. \\
\hline 4 & My professors in outpatient clinics use teaching methods appropriate to each subject. \\
\hline 5 & I feel that my clinical professors do their job with the right quality and professionalism. \\
\hline 6 & $\begin{array}{l}\text { My clinical professors as well as my staff are interested in improving the quality of teaching and learning activities in } \\
\text { outpatient clinics. }\end{array}$ \\
\hline 7 & I can improve my individual skills in outpatient clinics. \\
\hline 8 & I will receive my assessment from the outpatient professors on time. \\
\hline 9 & I feel that the assessment methods used in outpatient clinics are in line with the teaching methods. \\
\hline 10 & I have a very clear idea of the learning goals and consequences of my educational activities in outpatient clinics. \\
\hline 11 & I feel that the learning goals and outcomes of outpatient clinics have been properly achieved. \\
\hline 12 & I have been allowed to participate in educational activities and medical conferences \\
\hline
\end{tabular}

Clinical and Patient Care

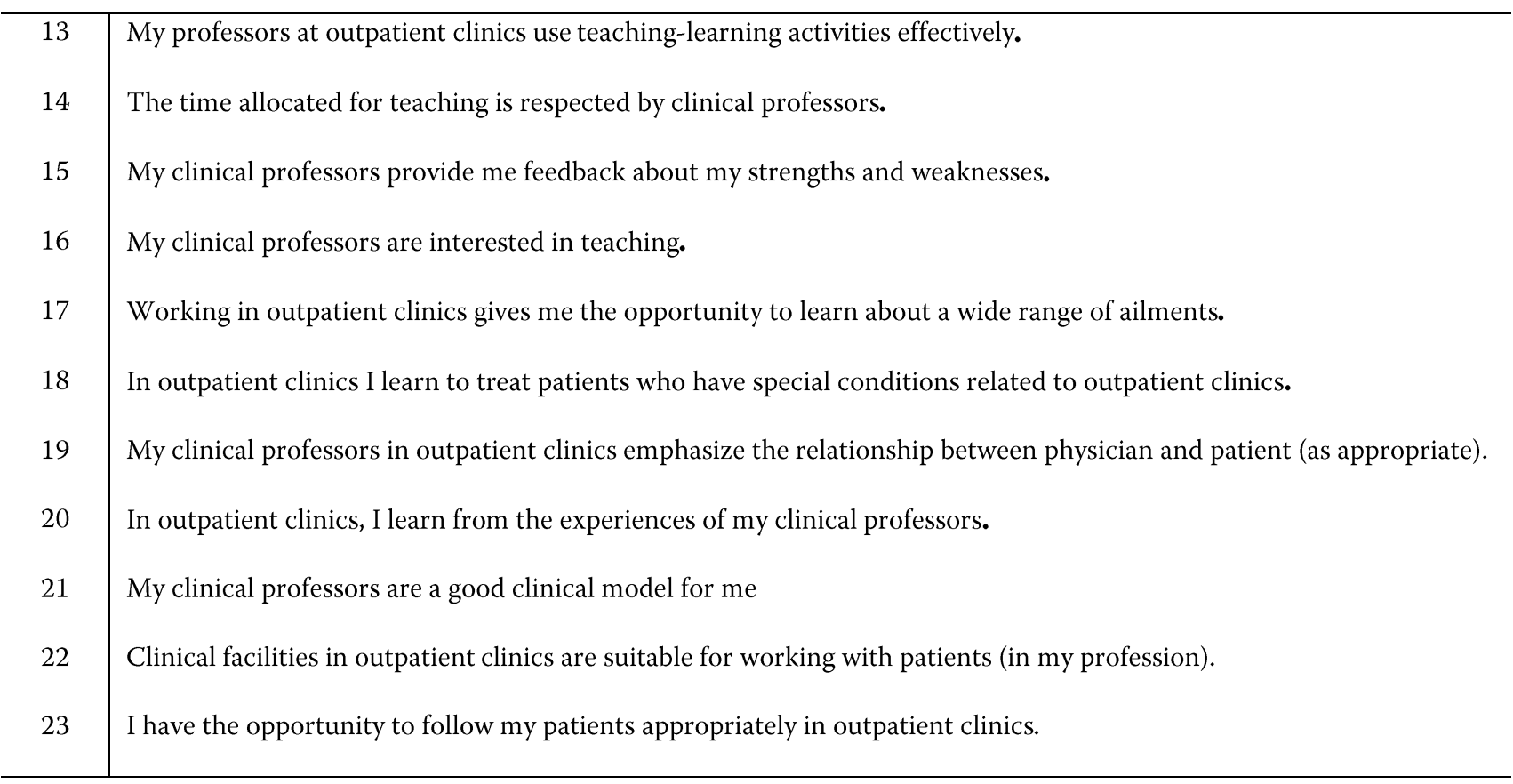

\begin{tabular}{l|l}
\hline \multicolumn{2}{l}{ Allocating time for non-clinical activities } \\
\hline 24 & I do not have the right time to see any patient in outpatient clinics \\
25 & My activities in outpatient clinics are clearly planned \\
\hline
\end{tabular}




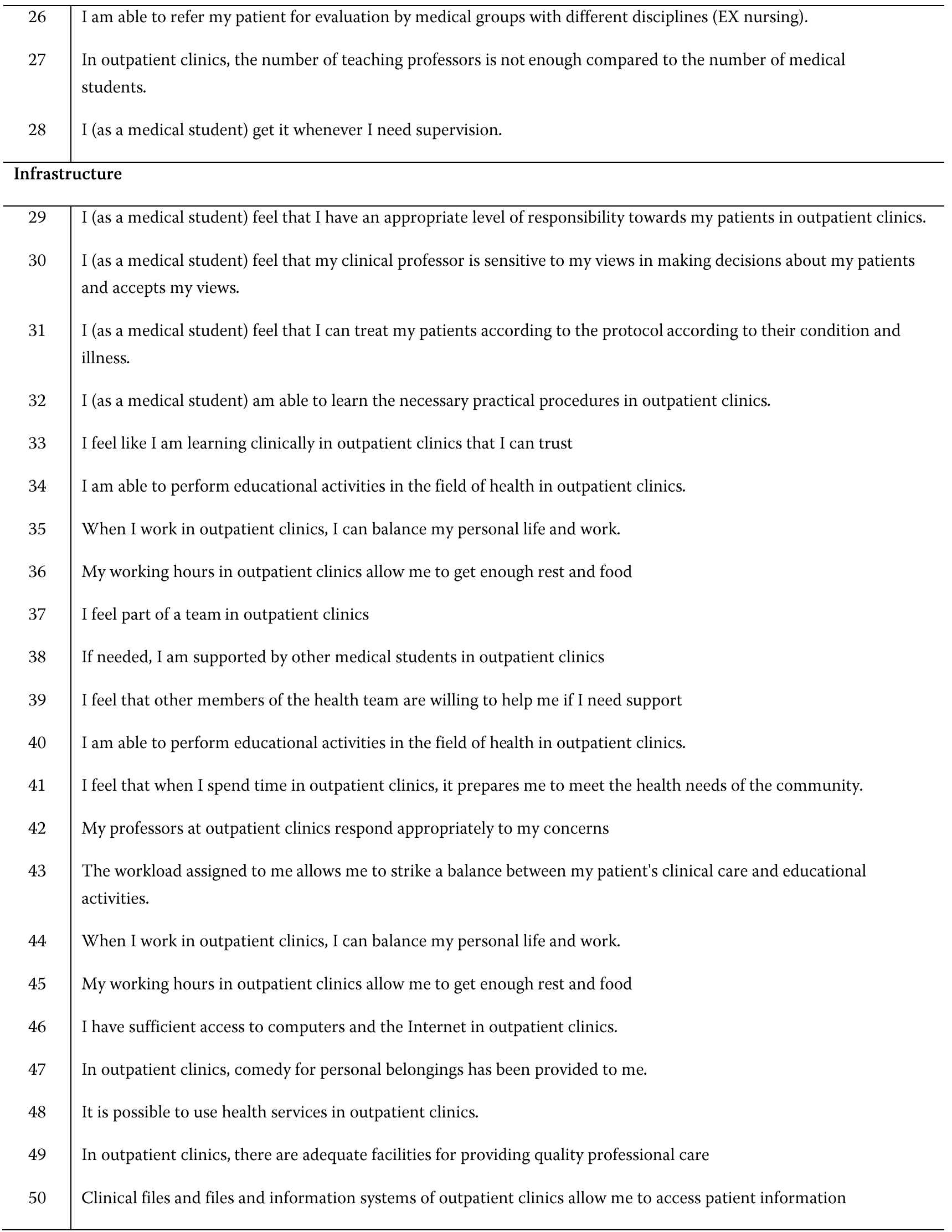




\section{References}

1. Bösner S, Roth LM, Duncan GF, Donner-Banzhoff $\mathrm{N}$ : Verification and feedback for medical students: an observational study during general practice rotations. Postgrad Med J. 2017; 93(1095):3-7.

2. Brotherton SE, Simon FA, Etzel SI. US graduate medical education, 2000-2001.Jama 2001; 286(9):1056-60.

3. Müller FH, Louw J. Learning environment, motivation and interest: Perspectives on selfdetermination theory. S Afr Psycol. 2004; 34.(2):169-90.

4. Schönrock-Adema J, Bouwkamp-Timmer $T$, van Hell EA, Cohen-Schotanus J. Key elements in assessing the educational environment: where is the theory?. Adv Health Science Edu. 2012; 17(5):727-42.

5.Dyrbye LN, Thomas MR, Harper W, Massie Jr FS, Power DV, Eacker A, Szydlo DW, Novotny PJ, Sloan JA, Shanafelt TD. The learning environment and medical student burnout: a multicentre study. Med Edu. 2009; 43(3):274-82.

6. Croft A, Carruthers D, Justice E. Undergraduate teaching in the outpatient clinic: Can we do better?. Med Teach. 2012; 34(8):674-682.

7. Aspegren K, Bastholt L, Bested KM, Bonnesen T, Ejlersen E, Fog I, Hertel T, Kodal T, Lund J, Madsen JS, Malchow-Møller A. Validation of the PHEEM instrument in a Danish hospital setting. Med Teach. 2007; 29(5):504-6.

8.Tomietto M, Saiani L, Saarikoski M, Fabris S, Cunico L, Campagna V, Palese A. Assessing quality in clinical educational setting: Italian validation of the clinical learning environment and supervision (CLES) scale. Ital J Occup Med Ergonomic. 2009 Jul 1; 31(3 Suppl B):B49-55.

9. de Oliveira Filho GR, Vieira JE, Schonhorst L. Psychometric properties of the Dundee Ready Educational Environment Measure (DREEM) applied to medical residents. Med Teach. 2005; 27(4):343-7.
10. Riquelme A, Padilla O, Herrera C, Olivos T, Román JA, Sarfatis A, Solís N, Pizarro M, Torres P, Roff S. Development of ACLEEM questionnaire, an instrument measuring residents' educational environment in postgraduate ambulatory setting. Med Teach. 2013; 35(1):e861-6.

11. Haque $M$, Othman NS, Lutfi $\mathrm{SN}$, Islam $\mathrm{MZ}$, Rahman NA, Kibria GM, Haque AE, Majumder MA, Gnanou JV. Evaluation of out-patient care educational environment of National Defence University, Malaysia utilizing the ACLEEM Inventory. J Basic Clin Health Sciences. 2018; 2(2):45-52.

12. Faruque M, Haque M, Islam S, Shihab SF, Kamal ZM. Outpatient Educational Environment of Dental-Medical Colleges of Bangladesh Utilizing ACLEEM Questionnaire. J Global Pharm Tech. 2017; 9:41-7.

13. Parvizi MM, Amini M, Dehghani MR, Jafari $P$, Parvizi Z. Psychometric properties of the Persian version of the ambulatory care learning educational environment measure (ACLEEM) questionnaire, Shiraz, Iran. Adv Med Educ Prac. 2016; 7:559.

14. Salajegheh M, Bahmanbijari B, Shokouhi M, Safipour Afshar A, Beigzadeh A. Educational environment assessment at outpatient clinics in teaching hospitals of Kerman University of Medical Sciences, Iran, from residents' perspective based on the ACLEEM questionnaire. Strides Dev Med Educ. 2015; 12(1):119-30.

15. Moogari ZN, Koohpayehzadeh J, Roff S, Montazeri A, Arabshahi SK, Bigdeli S, Moosavi M, Azaminejad F, Tavousi M. Psychometric analysis of the ambulatory care learning education environment measure (ACLEEM) in Iran. Med J Islamic Republic Iran. 2015; 29:299.

16. Kuhpayezadeh J, Arabshahi SK, Bigdeli S, Javid G, Tavousi M, Mousavi M. Assessment of educational environment at outpatient clinics in teaching hospitals: residents' perspective based on the ACLEEM. Payesh (Health Monitor). 2014; 13(5):551-9. 
17. Rahmani A, Faraji M, Ahmadi M. Evaluation Quality of Ambulatory Medical Education in a Hospital Education. Edu Strat Med Sci. 2018; 11(3):158-65.

18. Hundertmark J, Apondo SK, Schultz JH. Integrating teaching into routine outpatient care: the design and evaluation of an ambulatory training concept (HeiSA). GMS J Med Educ. 2018; 35(1).

19. Gellman MD, Turner JR, editors. Enc Behav Med. Springer New York; 2013.

20. Hair Jr JF, Matthews LM, Matthews RL, Sarstedt M. PLS-SEM or CB-SEM: updated guidelines on which method to use. Int J Multivar Data Anal. 2017; 1(2):107-23.

21. Costello AB, Osborne J. Best practices in exploratory factor analysis: Four recommendations for getting the most from your analysis. Pract asses Res Eval. 2005; 10(1):7.

22. Brigman G, Wells C, Webb L, Villares E, Carey JC, Harrington K. Psychometric properties and confirmatory factor analysis of the student engagement in school success skills. Meas Eval Counsel Dev. 2015; 48(1):3-14.

23. Williams B, Onsman A, Brown T. Exploratory factor analysis: A five-step guide for novices. Australas J Para Med. 2010; 8(3).

24. Byrne BM. Choosing structural equation modeling computer software: Snapshots of LISREL, EQS, AMOS, and M plus. 